\title{
Comparison of Different Bleaching Protocols Efficacy on Artificially Tea-Stained Teeth up to 24 Months Post-Treatment
}

\author{
Koniaris Antonios $^{1 *}$, Antoniadou Maria ${ }^{1}$, Margaritis Vasileios ${ }^{2}$ and Kakaboura Afrodite ${ }^{1}$ \\ ${ }^{1}$ Department of Operative Dentistry, Dental School, National and Kapodistrian University of Athens, Greece \\ ${ }^{2}$ College of Health Sciences, Walden University, USA
}

Submission: December 07, 2020; Published: December 18, 2020

*Corresponding author: Koniaris Antonios, Department of Operative Dentistry, Dental School, National and Kapodistrian, University of Athens, Greece.

Abstract

Objective: In vitro investigation of four bleaching protocols efficiency, on artificially tea-stained human teeth, up to 24-month post-treatment.

Methods: 100 intact, extracted, human incisors were randomly divided ( $\mathrm{n}=4 \times 25 /$ group $)$ and underwent black tea staining. The bleaching protocols applied per group were: 1. (BH, at-home) 10\%CaP for 5 days (120min/day), repeated twice, 2. (BO1, in-office) $40 \% H P$ for 3 successive applications (15 min/application), repeated twice, 3. (B01, in-office) 40\%HP for 3 successive applications (15 min/application), repeated 3 times and 4. (BH+B01, at-home/in-office) starting with BH, interval of 2 days, followed by B01. The color was measured before bleaching(t0), right after staining(t1), after each bleaching procedure(t2), 3(t3), 6(t4) and 24 months(t5) after treatment, with a colorimeter (Braive Instruments) in CIEL*a*b*system. $\Delta \mathrm{E}^{*}$ values were calculated relative to t0. Statistical analysis was performed by Mann-Whitney U and Friedman and Wilcoxon Signed Ranks tests $(\mathrm{a}=0.01)$.

Results: All bleaching protocols, at $\mathrm{t} 2$ induced increase in $\mathrm{L}^{*}$, return of a* to before-staining values, shifting of $\mathrm{b}^{*}$ to blue (B01, BO2) and improvement of tooth color $\left(\Delta \mathrm{E}^{*}\right)$ with no statistically significant difference among protocols. All color coordinates presented gradual rebound at t3. Regarding $\Delta \mathrm{E}^{*}$, tooth color reached after-staining values for $\mathrm{BH}, \mathrm{BO1}, \mathrm{BO2}$ up to 24 months, while bleaching effect was partially preserved for $\mathrm{BH}+\mathrm{BO} 1$ group.

Conclusion: At-home and in-office bleaching protocols provided similar whitening effect on tea-stained teeth, immediate after application. However, rebound effect started at 3 and progressed up to 24 months post-treatment. The combination of at-home and in-office treatment showed relative better potential in bleaching color preservation.

Keywords: Tooth bleaching agents; Tooth discolorations; Carbamide peroxide; Hydrogen peroxide

\section{Introduction}

The percentage of patients who seek improvement of their smile's appearance by tooth color change increases exponentially. As a result, a wide range of bleaching procedures has been recommended for tooth whitening [1]. Numerous randomized clinical trials evaluate the bleaching efficacy on teeth which fall into the natural tooth color range. However, due to the high number of variables contributed to the bleaching techniques (e.g. chemical agents and concentrations, different application periods, number of sessions, time intervals between bleaching sessions, at-home or in-office procedure) a clear conclusion cannot be drawn in terms of which protocol induces the most reliable and long-lasting color change [2-5]. Some studies report that at-home bleaching provides better and more stable whitening effect than in-office protocols, others support the opposite, while similar results for both techniques have been also published [3,6,7]. Even a systematic review could not answer the relative questions that exist [8].

The aforementioned data are pertain to the bleaching of teeth with natural colors. Teeth with discoloration due to wine, coffee, tea, cola consumption or smoke, present an additional challenge. It should be highlighted that any bleaching impact seen in the natural tooth color may not be obtained for discolored teeth, because the latter one's present different reactions to the bleaching protocols [9]. Clinical trials with respect to color change 


\section{Advances in Dentistry \& Oral Health}

in discolored teeth after bleaching are rare and these do not lead to certain conclusions $[10,11]$. The majority of in vitro studies, which investigate the relation between extrinsic discoloration and bleaching, are focused on immediate and not on long-term effects of various bleaching treatments, using bovine and not human teeth [12-17]. However, in general, the color rebound through the post-bleaching period is considered as one of the most serious problems [18-20]. Therefore, the long-lasting color change provided by a bleaching protocol offers a considerable advantage. In addition, although bovine teeth or their enamel slabs are often utilized in experimental studies and show similarities with the human teeth, it is under consideration if these are reliable substitutes of the human teeth [21]. Furthermore, to the best of our knowledge, the in vitro studies conducted for stained teeth compare different single in-office or at-home bleaching protocols or compare the first versus the second technique [22,23]. Thus, examination of a combination of an in-office and at-home protocol for bleaching treatment emerges.

Thus, the objective of this study was to in vitro compare the efficiency of in-office, at-home and in-office followed by at-home bleaching protocols on artificially tea-stained human teeth for a period up to 24-month post-treatment. The null hypothesis was that no differences exist among the protocols in terms of color changes induced immediate after bleaching and that there is no statistically significant color reverse of stained bleached teeth through time regardless of the bleaching protocols. lightness that gradually blends with the surrounding tooth color. The color improvement seemed to be more noticeable in orange/brown discolorations compared to the dark brown/black ones. The different response of stains to bleaching agents, might be explained by the different stain history of each tooth (type, depth); therefore, the bleaching agent may not be as efficacious in different stained lesions.

\section{Materials and Methods}

The ethics committee of athens dental school approved this in vitro trial

The bleaching products used in this study are shown in Table 1.

Table 1: Tooth bleaching products used in the study.

\begin{tabular}{|c|c|c|}
\hline Materials & Serial Number & Composition \\
\hline $\begin{array}{c}\text { Opalescence PF } \\
\text { (Ultradent, } 505 \text { West Ultradent Drive } \\
\text { South Jordan, USA) } \\
\text { (at-home agent) }\end{array}$ & $\begin{array}{c}(474338,2014-09) \\
\text { (B7L44,2014-10) }\end{array}$ & $10 \%$ carbamide peroxide, potassium nitrate and fluoride \\
\hline $\begin{array}{l}\text { Opalescence Boost (Ultradent, } 505 \text { West Ultradent Drive } \\
\text { South Jordan, USA) } \\
\text { (in-office agent) }\end{array}$ & $\begin{array}{l}\text { (B7L1X,2014-03) } \\
\text { (B7QNX,2014-05) }\end{array}$ & $40 \%$ hydrogen peroxide, potassium nitrate and fluoride \\
\hline
\end{tabular}

\section{Sample preparation}

One hundred intact human central and lateral incisors, extracted for periodontal reasons, were selected. After extraction, each tooth was cleaned with a polishing brush (Kerr Dental) and paste (Clean Polish, Kerr), which was then thoroughly removed with air-water spray and kept in a thymol solution $(0.02 \%$ thymol in saline) at room temperature $\left(22 \pm 2^{\circ} \mathrm{C}\right)$. Then, the teeth were numbered at the root surface with a permanent black marker. The numbers were then covered with a clear nail polish. For staining, all teeth were immersed in a black tea solution (M\&S Fair Trade Earl Grey), at room temperature $\left(22 \pm 2^{\circ} \mathrm{C}\right)$ for 7 days, which was renewed daily. The solution was prepared by boiling 2 gr black tea in $100 \mathrm{ml}$ of distilled water, for 5 minutes. After staining, teeth were randomly allocated into four groups $(n=25)$. Four different bleaching protocols per group were applied, [BH: bleaching athome, B01: bleaching in-office simulating 2 visits, BO2 bleaching in-office simulating 3 visits, $\mathrm{BH}+\mathrm{BO} 1$ : combination of at home and in-office bleaching] (Table 2).

Table 2: Bleaching application protocols per group.

\begin{tabular}{|c|c|c|}
\hline Group & Bleaching Material \& (Group) & Protocol \\
\hline$(\mathrm{BH})$ & Opalescence $\mathrm{PF}(\mathrm{BH})$ & $\begin{array}{c}\text { Application of the agent for } 5 \text { days continuously }(120 \mathrm{~min} / \text { day) with trays followed by two days } \\
\text { without application. } \\
\text { This sequence was repeated two (2) times more (at-home procedure). }\end{array}$ \\
\hline (B01) & Opalescence Boost (B01) & $\begin{array}{c}\text { Three (3) successive applications of the agent, directly on the teeth, for } 15 \text { minutes per session/ } \\
\text { week. } \\
\text { This sequence was repeated for two (2) consecutive weeks (in-office procedure). }\end{array}$ \\
\hline (BO2) & Opalescence Boost (BO2) & $\begin{array}{l}\text { Three (3) successive applications of the agent, directly on the teeth, for } 15 \text { minutes per session/ } \\
\text { week. } \\
\text { This sequence was repeated for three (3) weeks, with an interval of one week without applica- } \\
\text { tion between the sessions/weeks (in-office procedure). }\end{array}$ \\
\hline$(\mathrm{BH}+\mathrm{B} 01)$ & $\begin{array}{l}\text { Opalescence PF + Opalescence } \\
\text { Boost }(\mathrm{BH}+\mathrm{BO} 1)\end{array}$ & $\begin{array}{l}\text { First, the protocol of group BH is followed and then after an interval of two (2) days, the protocol } \\
\text { of group B01 is applied (at-home + in-office procedures). }\end{array}$ \\
\hline
\end{tabular}


In groups 2 and 3 the bleaching agent was directly applied on tooth surfaces while in groups 1 and 4 through custom made trays. For tray preparation, the teeth were placed in jaw models (Frasaco GmbH, Tettnang, Germany) using a VPS impression material (Variotime, Heraeus/Kulzer). Following, custom made trays with reservoirs were manufactured out of these jaw models, over plaster casts, after taking alginate impressions (CAVEX). The reservoirs were made with a light-cured resin (LC Block-Out Resin, Ultradent) formed in a layer of $1 \mathrm{~mm}$ over the labial surface. A groove along the tooth neck (to prevent leakage of material during the splint usage) was also formed, with a fine round bur (005 SKU: CB1 of Drendel \& Zweiling). The trays were formed with a thermoplastic material (Soft-Tray Sheets 0,9mm, 5" $x 5$ ", Ultradent). The limits of the trays were placed $1 \mathrm{~mm}$ below the anatomical neck of the teeth. At the intervals, during and after the completion of bleaching cycles, the teeth of all groups were kept in artificial saliva solution (Saliva Orthana, Luborant -AS Pharma, Unit 119, The Commercial Centre, Picket Piece, Hampshire SP11 $6 \mathrm{RU}, \mathrm{UK}$ ) at $37^{\circ} \mathrm{C}$, renewed daily throughout the testing period and after that once a week until the final measurements.

\section{Color recording}

Tooth color was recorded with a colorimeter (Dr. Lange, "Micro colour LMC", Braive instruments, Belgium), in CIEL*a*b* system, calibrated in black and white values. The color was measured: before bleaching ( $\mathrm{t} 0)$, right after staining ( $\mathrm{t} 1)$, after the whole bleaching procedure completion per group (t2), 3 (t3), 6 (t4) and 24 (t5) months after treatment. Before each color measuring, the teeth were rinsed with spray-water for 5 seconds and dried with air for 5 seconds. Each recording was taken from the middle third of the labial surface of the teeth. A customized silicone matrix was used to achieve measurements from the same tooth position while this was placed in the colorimeter. Color changes $\left(\Delta \mathrm{E}^{*}\right)$ were calculated at each time recording relative to the measurement before bleaching (t0), based on the equation $\Delta \mathrm{E}^{*}=\left[\left(\Delta \mathrm{L}^{*}\right) 2+\right.$ $\left.\left(\Delta \alpha^{*}\right) 2+(\Delta b) 2\right] 1 / 2$

\section{Statistical analysis}

After applying normality tests, dependent variables $\left(\mathrm{L}^{*}, \mathrm{a}^{*}, \mathrm{~b}^{*}\right.$ and $\Delta \mathrm{E}$ ) were not normally distributed, thus non-parametric tests (Mann-Whitney U and Friedman test) were used to investigate possible associations between the independent (groups and time) and the outcome variables. Also, a post-hoc analysis of the results using Wilcoxon Signed Ranks test was performed. Statistical analysis was performed using the program SPSS, IBM v21 and significance level was set at $1 \%(p$-value $=0.01)$ to reduce Type I (by chance) error as much as possible.

\section{Results}

The statistical power of the sample was very satisfactory (> 0.95), with a strong impact effect (effect size>0.87). The values of color parameters $\mathrm{L}^{*}, \mathrm{a}^{*}$ and $\mathrm{b}^{*}$ for the four groups, at all-time measurements are presented in Tables $3 \& 4$, accordingly and for $\Delta \mathrm{E}^{*}$ in Table 5 . Tea staining caused statistically significant decrease in $\mathrm{L}^{*}$, increase in $\mathrm{a}^{*}$ and no effect in $\mathrm{b}^{*}$ coordinate. Statistically higher $\mathrm{L}^{*}$ parameters were obtained right after bleaching ( $\mathrm{t} 2$ ) relative to the values recorded after staining ( $\mathrm{t} 1$ ), in all groups. Concerning $\mathrm{L}^{*}$ at $\mathrm{t} 3$ and $\mathrm{t} 4$ assessments, statistically decrease was observed relative to the values obtained immediately after bleaching application (t2). At 24 months post-bleaching period (t5), statistically significant reduction in $\mathrm{L}^{*}$ compared to the immediate after bleaching values ( $\mathrm{t} 2$ ) was observed for $\mathrm{BH}$ and $\mathrm{BH}+\mathrm{BO} 1$ protocols, whereas $\mathrm{BO} 1$ and $\mathrm{BO} 2$ subjected no statistical reduction. In respect of $\mathrm{a}^{*}$, the four bleaching protocols provided lower values relative to the staining analogues. At three (t3) and six ( $t 4)$ months recordings, a gradual increase of $a^{*}$ values were detected. At the final measurement ( $\mathrm{t} 5$ ), $\mathrm{a}^{*}$ values in all groups were statistically higher than the after bleaching $(\mathrm{t} 2)$ and the staining (t1) correspondence ones.

Table 3: Mean values (first line) and \pm standard deviations (second line) of the $L^{*}, a^{*}$ parameters for the bleaching protocols tested at all time measurements*.

\begin{tabular}{|c|c|c|c|c|c|c|c|c|c|c|c|c|}
\hline \multirow{2}{*}{ Group } & \multicolumn{6}{|c|}{$\mathbf{L}^{*}$} & \multicolumn{6}{|c|}{$\mathrm{a}^{*}$} \\
\hline & $t_{0}$ & t1 & $t_{2}$ & $t_{3}$ & $t_{4}$ & $t_{5}$ & $t_{0}$ & $t_{1}$ & $t_{2}$ & $t_{3}$ & $t_{4}$ & $t_{5}$ \\
\hline$(\mathrm{BH})$ & $\begin{array}{c}61.67 \\
{[1-4]} \\
( \pm 4.85)\end{array}$ & $\begin{array}{c}52.99 \\
{[1,5-7]} \\
( \pm 4.52)\end{array}$ & $\begin{array}{c}59.22 \\
{[5,8-10]} \\
( \pm 5.04)\end{array}$ & $\begin{array}{c}49,89 \\
{[2,6,8,11,12]} \\
( \pm 4.14)\end{array}$ & $\begin{array}{c}47,26 \\
{[3,7,9,11,13]} \\
( \pm 3,95)\end{array}$ & $\begin{array}{c}54,52 \\
{[4,10,12,13]} \\
( \pm 3,85)\end{array}$ & $\begin{array}{c}4,540 \\
{[1-4]} \\
( \pm 2,29)\end{array}$ & $\begin{array}{l}7,408 \\
{[1,5,6]} \\
( \pm 2,45)\end{array}$ & $\begin{array}{c}4,62 \\
{[5,7-9]} \\
( \pm 2,06)\end{array}$ & $\begin{array}{c}7,56[2,7,10] \\
( \pm 2,73)\end{array}$ & $\begin{array}{c}8,08 \\
{[3,8,11]} \\
( \pm 3,28)\end{array}$ & $\begin{array}{c}11,9[4,6,9-11 \\
( \pm 2,14)\end{array}$ \\
\hline (B01) & $\begin{array}{c}59.0 \\
{[1-5]} \\
( \pm 5.07)\end{array}$ & $\begin{array}{l}49.38 \\
{[1,6,7]} \\
( \pm 5.85)\end{array}$ & $\begin{array}{c}54.56 \\
{[2,6,8,9]} \\
( \pm 6.63)\end{array}$ & $\begin{array}{c}50,24 \\
{[3,8,10,11]} \\
( \pm 4,58)\end{array}$ & $\begin{array}{c}49,12 \\
{[4,9,10,12]} \\
( \pm 4,48)\end{array}$ & $\begin{array}{c}56,67 \\
{[5,7,11,12]} \\
( \pm 4,78)\end{array}$ & $\begin{array}{c}5,024 \\
{[1-4]} \\
( \pm 2,47)\end{array}$ & $\begin{array}{c}8,05 \\
{[1,5,6]} \\
( \pm 2,18)\end{array}$ & $\begin{array}{c}6,13 \\
{[5,7-9]} \\
( \pm 2,61)\end{array}$ & $\begin{array}{c}7,26[2,7,10] \\
( \pm 2,72)\end{array}$ & $\begin{array}{c}7,56 \\
{[3,8,11]} \\
( \pm 3,46)\end{array}$ & $\begin{array}{c}12,77[4,6,9- \\
11]( \pm 2,46)\end{array}$ \\
\hline (BO2) & $\begin{array}{c}61.33 \\
{[1-4]} \\
( \pm 4.83)\end{array}$ & $\begin{array}{c}51.76 \\
{[1,5,6]} \\
( \pm 3.54) \\
\end{array}$ & $\begin{array}{c}59.05 \\
{[2,5,7,8]} \\
( \pm 3.69) \\
\end{array}$ & $\begin{array}{c}52,51 \\
{[7,9,10]} \\
( \pm 3,11)\end{array}$ & $\begin{array}{c}50,78 \\
{[3,8,9,11]} \\
( \pm 2,94) \\
\end{array}$ & $\begin{array}{c}57,19 \\
{[4,6,10,11]} \\
( \pm 3,36)\end{array}$ & $\begin{array}{c}4,036 \\
{[1-4]} \\
( \pm 2,61)\end{array}$ & $\begin{array}{c}8,20 \\
{[1,5,6]} \\
( \pm 1,45) \\
\end{array}$ & $\begin{array}{c}5,66 \\
{[1,7-9]} \\
( \pm 1,40)\end{array}$ & $\begin{array}{c}7,95[2,7,11] \\
( \pm 1,75)\end{array}$ & $\begin{array}{c}6,90 \\
{[3,8,10,12]} \\
( \pm 1,54)\end{array}$ & $\begin{array}{c}11,66 \\
{[4,6,9,11,12]} \\
\quad \pm 1,6)\end{array}$ \\
\hline$(\mathrm{BH}+\mathrm{BO} 1)$ & $\begin{array}{c}61.33 \\
{[1-4]} \\
( \pm 5.49)\end{array}$ & $\begin{array}{c}50.26 \\
{[1,5,6]} \\
( \pm 3.91)\end{array}$ & $\begin{array}{c}63.21 \\
{[5-8]} \\
( \pm 4.05)\end{array}$ & $\begin{array}{c}52,43 \\
{[2,6,9,10]} \\
( \pm 3,34)\end{array}$ & $\begin{array}{c}50,16 \\
{[3,7,9,11]} \\
( \pm 2,85)\end{array}$ & $\begin{array}{c}55,74 \\
{[6,8,10,11]} \\
( \pm 3,28)\end{array}$ & $\begin{array}{c}6,48 \\
{[1-3]} \\
( \pm 2,58)\end{array}$ & $\begin{array}{c}11,20[1- \\
4] 1,4,5,6,7 \\
( \pm 3,12)\end{array}$ & $\begin{array}{c}6,03 \\
{[4,8-10]} \\
( \pm 2,32)\end{array}$ & $\begin{array}{c}8,91 \\
{[2,5,8,11,12]} \\
( \pm 2,63)\end{array}$ & $\begin{array}{c}7,95 \\
{[6,9,11,13]} \\
( \pm 2,72)\end{array}$ & $\begin{array}{c}12,98 \\
{[9,7,10,12,13]} \\
( \pm 2,67)\end{array}$ \\
\hline
\end{tabular}

*Same numbers within the rows for each parameter $\left(L^{*}, a^{*}\right)$ indicate statistically significant differences between time points for each group/row (Friedman test and post-hoc Wilcoxon Signed Ranks test, $p<0.01$ ). 


\section{Advances in Dentistry \& Oral Health}

Table 4: Mean values (first line) and \pm standard deviations (second line) of the $b^{*}$ parameter for bleaching protocols tested at all time measurements*.

\begin{tabular}{|c|c|c|c|c|c|c|}
\hline \multirow{2}{*}{ Group } & \multicolumn{6}{|c|}{$\mathbf{b}^{*}$} \\
\hline & $t_{0}$ & $t_{1}$ & $t_{2}$ & $t_{3}$ & $t_{4}$ & $t_{5}$ \\
\hline (BH) & $7,35[1-2]( \pm 1,82)$ & $7,94[3,4]( \pm 1,73)$ & $8,08[5,6]( \pm 1,75)$ & $6,02[1,3,5,7]( \pm 1,45)$ & $5,63[2,4,6,8]( \pm 1,61)$ & $8,36[7,8]( \pm 1,47)$ \\
\hline (B01) & $5,56[1,2]( \pm 1,98)$ & $6,10[3-5]( \pm 1,48)$ & $4,53[1,3,6]( \pm 1,52)$ & $5[4,7]( \pm 1,67)$ & $4,81[5,8]( \pm 1,87)$ & $7,06[2,6-8]( \pm 2,07)$ \\
\hline (B02) & $7,02[1-4]( \pm 2,13)$ & $6,85[5-8]( \pm 2,20)$ & $5,61[1,5,9]( \pm 2,23)$ & $5,53[2,6,10]( \pm 1,94)$ & $5,78[3,7,11]( \pm 1,98)$ & $8,38[4,8-11]( \pm 1,79)$ \\
\hline$(\mathrm{BH}+\mathrm{B01})$ & $6,69[1-3]( \pm 2,18)$ & $7,92[1,4-6]( \pm 2,14)$ & $5,52[4,7]( \pm 2,30)$ & $5,77[2,5,8]( \pm 3,15)$ & $5,38[3,6,8]( \pm 2,48)$ & $7,66[7-9]( \pm 2,11)$ \\
\hline
\end{tabular}

*Same numbers within the rows indicate statistically significant differences between time points for each group/row (Friedman test and post-hoc Wilcoxon Signed Ranks test, $p<0.01$.

Table 5: Mean values and \pm standard deviations of the $\Delta E^{\star}$ parameter for the bleaching protocols tested at all time measurements*

\begin{tabular}{|c|c|c|c|c|c|}
\hline \multirow{2}{*}{ Group } & \multicolumn{5}{|c|}{$\Delta \mathbf{E}$} \\
\cline { 2 - 6 } & $\mathbf{4}$ & $\mathbf{5}$ & $\mathbf{t}$ & $\mathbf{t}$ & $\mathbf{t}$ \\
\hline $\mathbf{( B H )}$ & $9,53[1-3]( \pm 5,61)$ & $5,20[1,4-6]( \pm 4,05)$ & $12,59[2,4,7]( \pm 6,43)$ & $15,22[3,5,7,8]( \pm 6,47)$ & $11,11[6,8]( \pm 5,55)$ \\
\hline (B01) & $10,36[1]( \pm 4,27)$ & $5,87[1-4]( \pm 5,04)$ & $9,48[2,5]( \pm 3,17)$ & $10,77[3,5,6]( \pm 3,37)$ & $9,17[4,6]( \pm 2,75)$ \\
\hline (B02) & $11,67[1]( \pm 5,93)$ & $7,31[1-4]( \pm 4,66)$ & $11,19[2]( \pm 6,63)$ & $12,43[3,5]( \pm 5,94)$ & $10,53[4,5]( \pm 4,75)$ \\
\hline (BH+B01) & $12,41[1-3]( \pm 5,31)$ & $4,88[1,4-6]( \pm 2,89)$ & $9,84[2,4,7]( \pm 4,55)$ & $11,71[5,7,8]( \pm 4,61)$ & $9,61[3,6,8]( \pm 3,61)$ \\
\hline
\end{tabular}

* *Same numbers within the rows indicate statistically significant differences between time points for each group/row (Friedman test and post-hoc Wilcoxon Signed Ranks test, $p<0.01)$. Same letters within the columns indicate statistically significant differences among the Groups $(1,2,3,4)$ for each time point/column (to, $t 1, t 2, t 3, t 4)$ (Mann-Whitney $U$ test, $p<0.01$ ) (no letters are noted because no differences were revealed).

Bleaching procedures statistically decreased $b^{*}$ parameters compared to the staining ones, except in BH group. No statistically significant changes were noticed in all groups through up to six months post-treatment ( $\mathrm{t} 3$ and $\mathrm{t} 4$ ) relative to their bleaching values recorded ( 2 2). After storage for 24 months, $b^{*}$ presented higher values ( $\mathrm{t} 5$ vs. $\mathrm{t} 2$ ) in $\mathrm{BO} 1, \mathrm{BO} 2$ and $\mathrm{BH}+\mathrm{BO} 1$ protocols whereas no difference observed for $\mathrm{BH}$. After bleaching ( $\mathrm{t} 2$ ), the four protocols presented statistically significant lower $\Delta \mathrm{E}^{*}$ values compared to the after staining ( $\mathrm{t} 1$ ) corresponding data. Through post-bleaching time $(\mathrm{t} 3, \mathrm{t} 4, \mathrm{t} 5), \Delta \mathrm{E}^{*}$ values were increased relative to the immediate after bleaching recordings ( $\mathrm{t} 2$ ), reaching statistically significant higher values for all protocols. Furthermore, the values had no statistically significant difference relative to the staining ones with the exception of $\mathrm{BH}+\mathrm{BO} 1$ treatment which was kept lower. No significant differences concerning $\Delta \mathrm{E}^{*}$ were noticed among the bleaching treatments applied at all time intervals.

\section{Discussion}

In general, intrinsic and extrinsic dyes influence the natural color of teeth. Regarding the extrinsic dyes, tobacco, dietary intakes, mouth rinses, metal salts, medication function as colorings [24,25].Tea is one of the most popular drinks and at the same time, it is considered as a possible extrinsic staining of the dentition, mostly because of the tannin which is a polyphenol macromolecule [26-28]. It is thought that the staining caused by tea is external and not internal because long length organic chains can hardly penetrate through enamel to reach the dentin [29]. Deposition of tannins on the outer tooth surface, which may bind to the enamel hydroxyapatite is believed to further promote tooth discoloration [30]. Macromolecules and dyes absorbed onto tooth surface, decrease the light reflectance and as a result, the teeth turn darker [31]. Bleaching technique, apart from natural tooth color improvement, is recommended for correcting tooth discoloration provided by various staining. The bleaching mechanism is based on the oxidative reaction induced by $\mathrm{OH}$ and $\mathrm{OOH}$ radicals - that are released from hydrogen or carbamide peroxide - and the tooth chromophore molecules. The latter ones are broken to smaller molecules, resulting in changing of the tooth optical properties [32]. This reaction is complex, so it has not clearly documented, up to now, how this whitening process functions [33]. In addition, the bleaching response seems to be differently influenced by each particular colorant, because their composition is not similar $[34,35]$. Therefore, the response of each stain to the various bleaching protocols is not predictable. 


\section{Advances in Dentistry \& Oral Health}

Experimental models, which simulate clinical conditions, have been designed through the years to study the efficiency of whitening methods on stained teeth. The most commonly used stains are coffee, red wine, tea, blood and chlorhexidine [16,3538].

The experimental tea-staining procedure followed in the current investigation is an accelerated approach, which has been applied by Kielbassa et al. [39]. In this study and concerning the teeth used, those of human origin were preferred than bovine ones. Although Attia et al. [15] reported that bovine and human dental substrates behave similarly during the bleaching process, the staining of human teeth and their bleaching implementation provide a better depiction of clinically relevant conditions. Furthermore, only incisor teeth were used for morphological similarity reasons among the samples and for convenience in color measurements by spectrometer due to their large extended flat buccal surface. Under the conditions of the current study, the storage media of the specimens played a significant role because the samples should be kept up to 2 years for the sequence of color recordings. Therefore, artificial saliva was employed instead of any other agent. It is established that mineral salts lost during bleaching can be replaced by the natural saliva [40,41]. The immediate after bleaching outcome is influenced by dehydration, therefore, one-week post-recording is commonly conducted to assign the validity of each bleaching protocol $[18,42]$. This specific period of measurement was skipped in the current study because the long-term color stability and not the immediate bleaching effect was the main objective.

In laboratory and clinical bleaching studies, commercially available shade color guides (e.g. Vita Classical, Vita 3D Master) are commonly utilized for color recording. As far as the present study is concerned, a colorimeter was chosen because shade guides are associated with serious drawbacks $[43,44]$. On the contrary, colorimeters present low risk of error and high rates of accuracy and repeatability between measurements $[23,45,46]$. Generally, for tooth color shade, the variation of $\mathrm{L}^{*}$ is more significant, followed by that of $\mathrm{b}^{*}$ and finally that of $\mathrm{a}^{*}[47,48]$. Moreover, $\mathrm{L}^{*}$ values, which depict the lightness/darkness appears to be the most relevant parameter to make comparisons under experimental conditions [45]. Lower $L^{*}$ values, obtained in the current study after tea staining, indicate tooth darkening. The a* value changes were in the direction of redness (higher values) and not greens, results which are in agreement with Lee et al. [49]. The polyphenols contained in black tea are the a-rubigins, which have red color and are mostly related with the staining capacity of tea [50]. The tea-flavins are another kind of polyphenol compound found in black tea, and although these present a yellow color, significant shifting to this direction $\left(b^{*}\right)$ was not detected in the current study. On the contrary, change of $b^{*}$ values to yellow axis was observed in Sulieman et al. study [16]. Differences in experimental conditions between the two investigations probably cause the controversial results. In Sulieman et al. [16] study, tea staining was performed through cut dentin and not only through enamel. Moreover, the different concentrations of the a-flavins in several tea brands used and the different immersed time chosen could be some additional contributor factors.

According to the findings of this study, the null hypothesis was confirmed concerning the absence of difference in whitening effect among the four bleaching protocols after the end of the procedure and it was rejected regarding the color preservation through posttreatment time. Bleaching, regardless of the methods used in the current study, considerably increased lightness ( $\left.\mathrm{L}^{*}\right)$ immediately after the application period and $\mathrm{L}^{*}$ was at first reduced after tea staining of the teeth. Changes in $\mathrm{L}^{*}$ values, individually, cannot determine the protocol with the best whitening performance because each group presented different initial (t0) and after staining ( $t 1) L^{*}$ values. However, the percentage difference per group ( $\mathrm{t} 1-\mathrm{t} 2 / \mathrm{t} 1)$ can function as an indicator. The relative values were as follows: BH $(11,7 \%), \mathrm{BO} 1(10,5 \%), \mathrm{BO} 2(14 \%)$ and $\mathrm{BH}+\mathrm{BO} 1(25,8 \%) \mathrm{L}^{*}$ increase. It is obvious that the combined at-home/in-office technique is appeared as the most intense bleaching procedure. However, for all groups, $\mathrm{L}^{*}$ started to drop down already after 3 months post-bleaching, with a different rate for each protocol. Specifically, although the two in-office techniques presented $\mathrm{L}^{*}$ rebound, these were proved more efficient to preserve the whitening effect than the at-home and the at-home/in-office techniques.

Regarding a*, after bleaching, the values reversed to the initial ones (before staining) per group. After bleaching, through time, gradual rebound was observed relative to the after control, regardless the group. At 24-month assessment, higher values were recorded than those of control for each stained group. It is rather difficult to explain the phenomenon. The aging of the end products of the oxidative reaction as well as, the remaining tea chromophore molecules may provide shifting to the green direction. Although tea-staining had no influence on all $\mathrm{b}^{*}$ coordinates, bleaching decreased the correspondence $b^{*}$ values per group except of $\mathrm{BH}$, leading to blueness. Through time, $\mathrm{b}^{*}$ presented graduate increase up to values higher than the after bleaching and higher than those of the natural teeth (initial values) except of BH. Although, generally, the higher the $\Delta \mathrm{E}^{*}$ difference, the greater the color change, in clinical point of view, the calculation of $\Delta \mathrm{E}^{*}$ by itself has no practical significance. It should be combined with the clinical perception threshold (PT: perceptibility threshold), which stands for the color difference that is clinically distinct from/to the $50 \%$ of the observers [51]. In this study, the recommended value of 2.7 for the PT was used for comparison [52,53]. According to our results, $\Delta \mathrm{E}^{*}$ values obtained either through the tea-staining process or bleaching were higher than the limit of 2.7 value. Therefore, in any combination between time intervals, and for all groups the color difference recorded was clinically distinct from/to the $50 \%$ of the observers.

$\Delta \mathrm{E}^{*}$ shows the magnitude of the change and not the direction of the change in the three coordinates of the CIELab system. 


\section{Advances in Dentistry \& Oral Health}

Bleaching, upon ending of the procedure, improved color $(\Delta \mathrm{E})$ relative to stained analogues, with no difference among the protocols. Opalescence PF (BH group) based on 10\% carbamide peroxide is considered as milder bleaching agent than Opalescence Boost, which contains 40\% hydrogen peroxide (BO1 and BO2 groups). Therefore, it should expect that Opalescence Boost could obtain stronger immediate color change $[54,55]$. On the other hand, generally in bleaching protocols, it is not clear if higher concentrations provide better whitening results or a combination of application time and agent influences the bleaching effect [5658]. The significantly longer application time of Opalescence PF (1.800 min) compared to Opalescence Boost ( 90 for B01 and 135 min for B02) may be associated with the absence of difference concerning the whitening effect of the protocols. Therefore, time may be the dominant variable for color change for the tea-stained teeth and not the concentration of the bleaching agent.

The additional application of a strong agent after at-home procedure $(\mathrm{BH}+\mathrm{BO} 1)$ did not show the potential for further whitening outcome. As far as, the majority of chromophore molecules have been broken by oxygen within the first phase of the protocol $(\mathrm{BH})$, the influence of the second phase (BO1) may be negligible. However, it is interesting that this protocol achieved more successful long-lasting effect than all the others applied. Indeed, the bleaching effect was short-lasting for all the protocols. The teeth started to recover their color three months after the end of the treatment. After twenty-four months, their color reached that received after staining, except of those treated by at-home/ in-office procedure, which preserved percentage of the bleaching effect. Although the bleaching effect on stained teeth has been investigated in some studies, serious differences are identified in comparison with the experimental conditions followed by this study $[12-17,39]$. Type and preparation of samples exposed dental tissue, staining type and procedure, color recording method, bleaching protocols, follow-up period etc. are some of the differences that can be mentioned. The wide diversity of the factors involved causes great difficulties for comparison of our findings with those of previous studies.

\section{Conclusion}

Within the limitations of this study the following conclusions can be derived:

a) Artificially tea-staining led to decrease in $\mathrm{L}^{*}$ values of teeth, shifting of $a^{*}$ to redness and no changes in $b^{*}$ values.

b) All bleaching protocols, immediate after completion of the procedure, induced: a) improvement in lightness $\left(\mathrm{L}^{*}\right)$ ranged from $11,7 \%$ for at-home protocol to $25,8 \%$ for the combined athome/in-office one, b) reverse of $a^{*}$ values to before staining status, c) shifting of $b^{*}$ values to blue direction for in-office and at-home methods and, d) improvement of tooth color ( $\Delta \mathrm{E})$ with no difference among the protocols.

c) Through post-treatment period, $\mathrm{L}^{*}, \mathrm{a}^{*}$ and $\mathrm{b}^{*}$ coordinates presented gradual rebound starting after three (3) up to twenty- four (24) months.

d) Within 24-month post-treatment, the tooth color $\left(\Delta \mathrm{E}^{*}\right)$ reached the after-staining values for in-office and at-home protocols. Bleaching effect was partially preserved only for athome/in-office procedure.

e) All $\Delta \mathrm{E}$ values obtained either through the tea-staining or the bleaching process were clinically distinct from the $50 \%$ of the observers ( $>2.7)$.

\section{References}

1. Luque Martinez A, Reis M, Schroeder MA, Munoz AD, Loguercio D, et al. (2016) Comparison of efficacy of tray-delivered carbamide and hydrogen peroxide for at-home bleaching: a systematic review and meta-analysis. Clin oral investig 20(7): 1419-1433.

2. Bernardon JK, Sartori N, Ballarin A, Perdigão J, Lopes GC, et al. (2010) Clinical performance of vital bleaching techniques. Oper dent 35(1): 3-10.

3. Turkun M, Celik EU, Aladag A, Gokay N (2010) One-year clinical evaluation of the efficacy of a new daytime at-home bleaching technique: official publication of the American Academy of Esthetic Dentistry. Journal of esthetic and restorative dentistry 22(2): 139-146.

4. Basting RT, Amaral FL, Franca FM, Florio FM (2012) Clinical comparative study of the effectiveness of and tooth sensitivity to $10 \%$ and $20 \%$ carbamide peroxide home-use and $35 \%$ and $38 \%$ hydrogen peroxide in-office bleaching materials containing desensitizing agents. Oper dent 37(5): 464-473.

5. Alonso de la Pena V, Lopez Raton M (2014) Randomized clinical trial on the efficacy and safety of four professional at-home tooth whitening gels. Oper dent 39(2): 136-143.

6. Tay LY, Kose C, Herrera DR, Reis A, Loguercio AD (2012) Long-term efficacy of in-office and at-home bleaching: a 2-year double-blind randomized clinical trial. Am J Dent 25(4): 199-204.

7. Giachetti L, Bertini F, Bambi C, Nieri M, Scaminaci Russo D (2010) A randomized clinical trial comparing at-home and in-office tooth whitening techniques: A nine-month follow-up. Journal of the American Dental Association 141(11): 1357-1364.

8. de Geus JL, Wambier LM, Kossatz S, Loguercio AD, Reis A (2016) Athome vs In-office Bleaching: A Systematic Review and Meta-analysis. Oper dent 41(4): 341-356.

9. Carlos NR, Pinto A, do Amaral F, Franca F, Turssi CP, et al. (2019) Influence of Staining Solutions on Color Change and Enamel Surface Properties During At-home and In-office Dental Bleaching: An in Situ Study. Oper dent 44(6): 595-608.

10. de Geus JL, Beltrame FL, Wang M, Avula B, Khan IA, et al. (2018) Determination of nicotine content in teeth submitted to prophylaxis and in-office bleaching by gas chromatography-mass spectrometry (GC-MS). Clin oral investg 22(9): 3043-3051.

11. Zhao K, Zong L, Zhang Q, Att W (2013) Clinical comparison between two bleaching techniques: a 180-day follow-up study, Quintessence international 44(8): 601-607.

12. Karadas M, Duymus ZY (2015) In Vitro Evaluation of the Efficacy of Different Over-the-Counter Products on Tooth Whitening. Brazilian dental journal 26(4): 373-377.

13. Juliana Zavala Bazzi, Marcio José Fraxino Bindo, Rodrigo Nunes Rached, Rui Fernando Mazur, Sergio Vieira, et al. (2012) The effect of at-home bleaching and toothbrushing on removal of coffee and cigarette smoke stains and color stability of enamel. J Am Dent Assoc 143(5): e1-7. 


\section{Advances in Dentistry \& Oral Health}

14. Penha KF, Sousa AC, Oliveira CA, de Andrade RS, Vasconcelos DF (2018) A swift, easy and cheap protocol to evaluate the tooth bleaching in vitro. J Clin Exp Dent 10(6): e579-e584.

15. Attia ML, Aguiar FH, Mathias P, Ambrosano GM, Fontes CM, et al. (2009) The effect of coffee solution on tooth color during home bleaching applications. Am J Dent 22(3): 175-179.

16. Sulieman M, Addy M, Rees JS (2003) Development and evaluation of a method in vitro to study the effectiveness of tooth bleaching. J dent 31(6): 415-422.

17. Vaez SC, Correia ACC, Santana TR, Santana MLC, Peixoto AC, et al (2019) A simple method to increase the bleaching effectiveness of high-concentrated carbamide peroxide used for in-office bleaching. Int J Esthet Dent 14(3): 324-332.

18. Moghadam FV, Majidinia, S Chasteen J, Ghavamnasiri M (2013) The degree of color change, rebound effect and sensitivity of bleached teeth associated with at-home and power bleaching techniques: A randomized clinical trial, European journal of dentistry 7(4): 405-411.

19. Moghadam FV, Majidinia S, Chasteen J, Ghavamnasiri M (2013) The degree of color change, rebound effect and sensitivity of bleached teeth associated with at-home and power bleaching techniques: A randomized clinical trial, European journal of dentistry 7(4): 405-411.

20. Bersezio C, Ledezma P, Estay J, Mayer C, Rivera O, et al. (2019) Color Regression and Maintenance Effect of Intracoronal Whitening on the Quality of Life: RCT-A One-year Follow-up Study, Operative dentistry 44(1): 24-33.

21. Yassen GH, Platt JA, Hara AT (2011) Bovine teeth as substitute for human teeth in dental research: a review of literature. J Oral Sci 53(3): 273-82.

22. Borges BC, Borges JS, de Melo CD, Pinheiro IV, Santos AJ, et al. (2011) Efficacy of a novel at-home bleaching technique with carbamide peroxides modified by CPP-ACP and its effect on the microhardness of bleached enamel. Oper dent 36(5): 521-528.

23. Sulieman M, MacDonald E, Rees JS, Newcombe RG, Addy M (2006) Tooth bleaching by different concentrations of carbamide peroxide and hydrogen peroxide whitening strips: an in vitro study, Journal of esthetic and restorative dentistry: official publication of the American Academy. J Esthet Restor Dent 18(2): 93-100.

24. Kumar A, Kumar V, Singh J, Hooda A, Dutta S (2012) Drug-induced discoloration of teeth: an updated review. Clin Pediatr (Phila) 51(2): 181-5.

25. Dalrymple A, Badrock TC, Terry A, Barber M, Hall PJ, et al. (2018) Assessment of enamel discoloration in vitro following exposure to cigarette smoke and emissions from novel vapor and tobacco heating products. Am J Dent 31(5): 227-233.

26. Samorodnitzky-Naveh GR, Geiger SB, Levin L (2007) Patients' satisfaction with dental esthetics. Journal of the American Dental Association 138(6): 805-808

27. Khan N, Mukhtar H (2007) Tea polyphenols for health promotion. Life Sci 81(7): 519-33

28. Hattab FN, Qudeimat MA, Al-Rimawi HS (1999) Dental discoloration: an overview. J esthet dent 11(6): 291-310.

29. Rezende M, Loguercio AD, Reis A, Kossatz S (2013) Clinical effects of exposure to coffee during at-home vital bleaching, Operative dentistry 38(6): E229-E236.

30. Proctor GB, Pramanik R, Carpenter GH, Rees GD (2005) Salivary proteins interact with dietary constituents to modulate tooth staining, Journal of dental research 84(1): 73-78.

31. Plotino G, Buono L, Grande MN, Pameijer CH, Somma F (2008) Nonvital tooth bleaching: a review of the literature and clinical procedures. J Endod 34(4): 394-407.

32. Carey CM (2014) Tooth whitening: what we now know. J Evid Based Dent Pract 14(Suppl): 70-76.

33. Eimar H, Siciliano R, Abdallah MN, Nader SA, Amin WN, et al. (2012) Hydrogen peroxide whitens teeth by oxidizing the organic structure. J dent 40(Suppl 2): e25-33.

34. Al-Angari SS, Hara AT (2016) A conservative approach to esthetically treat stained arrested caries lesions. Quintessence international 47(6): 499-504.

35. Young N, Fairley P, Mohan V, Jumeaux C (2012) A study of hydrogen peroxide chemistry and photochemistry in tea stain solution with relevance to clinical tooth whitening. J dent 40(Suppl 2): e11-6.

36. Pretty IA, Edgar WM, Higham SM (2001) The use of QLF to quantify in vitro whitening in a product testing model. British dental journal 191(10): 566-569.

37. Freccia WF, Peters DD (1982) A technique for staining extracted teeth: a research and teaching aid for bleaching. J Endod 8(2): 67-69.

38. Azer SS, Hague AL, Johnston WM (2010) Effect of $\mathrm{pH}$ on tooth discoloration from food colorant in vitro. J dent 38(Suppl 2): e106-e109.

39. Kielbassa AM, Beheim-Schwarzbach NJ, Neumann K, Nat K, Zantner C (2009) In vitro comparison of visual and computer-aided pre- and posttooth shade determination using various home bleaching procedures. J prosthet dent 101(2): 92-100

40. Sa Y, Sun L, Wang Z, Ma X, Liang S, et al. (2013) Effects of two in-office bleaching agents with different $\mathrm{pH}$ on the structure of human enamel: an in situ and in vitro study. Oper dent 38(1): 100-110.

41. Justino LM, Tames DR, Demarco FF (2004) In situ and in vitro effects of bleaching with carbamide peroxide on human enamel, Oper dent 29(2): 219-225.

42. Burki Z, Watkins S, Wilson R, Fenlon M (2013) A randomised controlled trial to investigate the effects of dehydration on tooth colour. I dent 41(3): 250-257.

43. Russell MD, Gulfraz M, Moss BW (2000) In vivo measurement of colour changes in natural teeth. J oral rehabil 27(9): 786-792.

44. Paul S, Peter A, Pietrobon N, Hammerle CH (2002) Visual and spectrophotometric shade analysis of human teeth. J dent res 81(8): 578-582.

45. Dietschi D, Benbachir N, Krejci I (2010) In vitro colorimetric evaluation of the efficacy of home bleaching and over-the-counter bleaching products. Quintessence int 41(6): 505-516.

46. Tung FF, Goldstein GR, Jang S, Hittelman E (2002) The repeatability of an intraoral dental colorimeter. The Journal of prosthetic dentistry 88(6): 585-590.

47. Joiner (2004) Tooth colour: A review of the literature. J dent 32(Suppl 1): 3-12.

48. Joiner, Luo W (2017) Tooth colour and whiteness: A review. J dent 67s: S3-s10.

49. Lee RJ, Bayne A, Tiangco M, Garen G, Chow AK, (2012) Prevention of tea-induced extrinsic tooth stain. Int J Dent Hyg 12(4): 267-272.

50. Robertson, Bendall DS (1983) Production and HPLC analysis of black tea theaflavins and thearubigins during in vitro oxidation, Phytochemistry 22(4): 883-887.

51. Khashayar G, Bain PA, Salari S, Dozic A, Kleverlaan CJ, et al. (2014) Perceptibility and acceptability thresholds for colour differences in dentistry. J dent 42(6): 637-644. 
52. Douglas RD, Steinhauer RT, Wee AG (2007) Intraoral determination of the tolerance of dentists for perceptibility and acceptability of shade mismatch. J prosthet dent 97(4): 200-208.

53. Da Silva JD, Park SE, Weber HP, Ishikawa-Nagai S (2008) Clinical performance of a newly developed spectrophotometric system on tooth color reproduction. J prosthet dent 99(5): 361-368.

54. Dourado Pinto AV, Carlos NR, Amaral F, Franca FMG, Turssi CP, Basting RT (2019) At-home, in-office and combined dental bleaching techniques using hydrogen peroxide: Randomized clinical trial evaluation of effectiveness, clinical parameters and enamel mineral content. Am J Dent 32(3): 124-132.

55. Bersezio J, Martin MV, Prieto P, Meneses P, Angel G, et al. (2019) One-year bleaching efficacy using two HP products with different $\mathrm{pH}$ : A double-blind randomized clinical trial, Journal of esthetic and restorative dentistry: official publication of the American Academy. J Esthet Dent 31(5): 493-499.
56. Acuna ED, Parreiras SO, Favoreto MW, Cruz GP, Gomes A, et al, (2019) In-office bleaching with a commercial $40 \%$ hydrogen peroxide gel modified to have different pHs: Color change, surface morphology, and penetration of hydrogen peroxide into the pulp chamber, Journal of esthetic and restorative dentistry: official publication of the American Academy. J Esthet Dent.

57. Rodriguez-Martinez J, Valiente M, Sanchez-Martin MJ (2019) Tooth whitening: From the established treatments to novel approaches to prevent side effects, Journal of esthetic and restorative dentistry: official publication of the American Academy. J Esthet Dent 31(5): 431440 .

58. Traviglia D, Re L, De Micheli, Bianchi AE, Coraini C (2019) Speed bleaching: the importance of temporary filling with hermetic sealing. Int J Esthet Dent 14(3): 310-323. 